\title{
PARTICLE SWARM OPTIMIZATION PADA METODE KNN EUCLIDEAN DISTANCE BERBASIS VARIASI JARAK UNTUK PENILAIAN AKREDITASI LEMBAGA KURSUS
}

\author{
Herry Adi Chandra \\ Fakultas Teknologi Informasi \\ Universitas Islam Kalimantan Muhammad Arsyad Al Banjari Banjarmasin \\ herrysbc@gmail.com
}

\begin{abstract}
ABSTRAK
Penilaian kinerja terhadap Lembaga kursus merupakan salah satu pola penguatan kelembagaan yang dilakukan oleh Direktorat pembinaan kursus dan pelatihan dengan berbagai parameter.Akan tetapi system penilaian akreditasi masih memakai cara yg sangat manual, dengan melakukan penilaian ke lembaga kursus dan pelatihan .oleh karena itu tugas pokok dan fungsi Badan Akreditasi Nasional Pendidikan Non Formal (BAN-PNF) adalah melaksanakan akreditasi terhadap Lembaga Kursus dan Pelatihan (LKP). Akreditasi adalah kegiatan penilaian kelayakan satuan beserta program PNF berdasarkan atas kriteria yang telah ditetapkan. Untuk menilai kelayakan tersebut disusun instrumen akreditasi yang mengacu pada Standar Nasional Pendidikan (SNP) sebagaimana ditetapkan melalui Peraturan Pemerintah Republik Indonesia Nomor 32 Tahun 2013 tentang Perubahan atas Peraturan Pemerintah Republik Indonesia Nomor 19 Tahun 2005, yang mencakup delapan standar. Dengan menggunakan metode KNN dan optimasi Particle Swarm Optimization untuk mningkatkan akurasi dengan jumlah data yg sangat bnyak hasil penelitian juga mendapatkan tingkat akurasi yang optimal pada rumus variasi jarak yaitu $K$ - Nearest neighbor Euclidean distance dari 96,60\%, sampai 99,69\%. Dapat dilihat jelas adanya kenaikan yang dihasilkan, walaupun tidak terlalu besar yaitu hanya sebesar 3,09 \%.jadi untuk meningkatkan hasil akurasi yang optimal maka K-NN Euclidean distance di optimasi dengan Particle Swarm Optimization, yang mampu meningkatkan nilai akurasi sehingga dapat menjadi acuan yang sangat baik untuk klasifikasi akreditasi Lembaga kursus.
\end{abstract}

Kata Kunci : $K-N N$, Euclidean Distance, Particle Swarm Optimization

\section{PENDAHULUAN}

Sistem pendidikan nasional sebagai tersebut dalam Undang-Undang Republik Indonesia No. 20 Tahun 2003 tentang Sistem Pendidikan Nasional (selanjutnya: UU RI No.20/2003), adalah keseluruhan komponen pendidikan yang saling terkait secara terpadu untuk mencapai tujuan pendidikan nasional dimana jalur pendidikan terdiri atas pendidikan formal, nonformal, dan informal yang dapat saling melengkapi dan memperkaya serta dapat diselenggarakan dengan sistem terbuka melalui tatap muka dan/atau melalui jarak jauh .

Salah satu jalur pendidikan adalah pendidikan non formal (selanjutnya disebut PNF) yang dapat dilaksanakan secara terstruktur dan berjenjang. Pendidikan nonformal diselenggarakan bagi warga masyarakat yang memerlukan layanan pendidikan yang berfungsi sebagai pengganti, penambah, dan/atau pelengkap pendidikan formal dalam rangka mendukung pendidikan sepanjang hayat dan berfungsi mengembangkan potensi peserta 
didik dengan penekanan pada penguasaan pengetahuan dan keterampilan fungsional serta pengembangan sikap dan kepribadian profesional. PNF telah melaksanakan 5000 program pendidikan keterampilan hidup, 3 jenis pendidikan usia dini dengan 56.544 program, 10.000 program pedidikan pembedayaan perempuan, 120.000 pendidikan keaksaraan, 187 jenis ketrampilan dan pelatihan dalam bentuk kursus dengan 13.000 program 5000 serta Pusat Kegiatan Belajar Masyarakat (PKBM). PNF juga telah dikembangkan oleh pemerintah melalui Unit Pelaksana Teknis (UPT) pusat dan daerah dengan berbagai pengembangan model dalam penyelenggaraan program. UPT tersebut adalah Pusat Pengembangan Pendidikan Nonformal dan Informal (P2PNFI) 5 Balai Pengembangan Pendidikan Luar Sekolah dan Pemuda (BPPLSP), 23 Balai Pengembangan Kegiatan Belajar (BPKB), 350 Sanggar Kegiatan Belajar (SKB). Dengan demikian dilihat dari sisi jumlah, PNF sudah cukup maju, namun dilihat dari sisi mutu dan kelayakan, kinerja PNF masih perlu ditingkatkan secara

berkelanjutan. Ilmu dan teknologi terus berkembang seiring dan sejalan dengan

perkembangan dan tuntutan kehidupan masyarakat. Kondisi ini memaksa para pengelola PNF untuk terus bergerak maju dalam memberikan layanan pendidikan yang layak bagi warga masyarakat, sehingga mereka dapat merebut peluang yang terus berkembang. Hanya warga masyarakat yang memiliki pengetahuan, keterampilan, dan

sikap maju yang akan mampu memanfaatkan lingkungan yang terus

berkembang. Sebagai upaya untuk mengenali dan menditeksi program dan satuan PNF yang perlu ditingkatkan kelayakannya, maka program dan satuan PNF yang ada perlu diakreditasi.Salah satu tugas pokok dan fungsi Badan Akreditasi Nasional Pendidikan Non Formal (BANPNF) adalah melaksanakan akreditasi terhadap Lembaga Kursus dan Pelatihan (LKP). Akreditasi adalah kegiatan penilaian kelayakan satuan beserta program PNF berdasarkan atas kriteria yang telah ditetapkan. Untuk menilai kelayakan tersebut disusun instrumen akreditasi yang mengacu pada Standar Nasional Pendidikan (SNP) sebagaimana ditetapkan melalui Peraturan Pemerintah Republik Indonesia Nomor 32 Tahun 2013 tentang Perubahan atas Peraturan Pemerintah Republik Indonesia Nomor

19 Tahun 2005, yang mencakup delapan standar yaitu :

1. Standar Kompetensi Lulusan

2. Standar Isi,

3. Standar Proses

4. Standar Pendidik danTenaga Kependidikan,

5. Standar Sarana dan Prasarana

6. Standar Pengelolaan

7. Standar Pembiayaan

8. Standar Penilaian Pendidikan.

Instrumen akreditasi digunakan untuk

memperoleh data berkaitan dengan 8 (delapan) SNP yang menggambarkan

kondisi LKP secara obyektif. Untuk itu, instrumen ini harus diisi oleh pengelola LKP atau pihak yang bertanggung jawab atas penyelenggaraan LKP. Jawaban terhadap pertanyaan/pernyataan harus sesuai dengan prosedur akreditasi Lembaga Kursus dan Pendidikan yang telah ditetapkan oleh BANPNF [1].

Sebelum dan sampai tahun 2014 Akreditasi dilakukan pada lembaga hanya kata terakreditasi tidak melalui tingkatan A, B, C tetapi telah terbit isia form 2014 yang dilaksanakan pada penilaian 2015 tingkatan sudah diberlakukan yang artinya sebelumnya hanya kelangkapan 
administrasi yaitu Administrasi Mayor harus terpenuhi 100\% Minor $80 \%$ dan Ovserved 90\% apabila terpenuhi maka Lembaga Kursus tersebut sudah terakreditasi tetapi setelah format isian tahun 2014 yang berlaku di tahun 2015 sistem penilain berubah menjadi tingkatan A, B, C maka dalam sistem penilai terjadi perubahan sistem penilaian dari kelengkapan Administrasi yang harus dipenuhi menjadi nilai dengan angka-angka yang dijumlahkan hingga menjadi Akreditasi $\mathrm{A}, \mathrm{B}$, dan $\mathrm{C}$. Dalam hal penilaian dari Delapan Standart terdapat nilai-nilai ada beberapa kelemahan penilaian Jumlah Penilaian pada Delapan Standar dijumlahkan seluruhnya kemudian total nilai menjadi range nilai yaitu $\mathrm{A}, \mathrm{B}$ dan $\mathrm{C}$. Dalam Penilain ini Akreditasi melalui proses berkas diperiksa kemudian Desk Asseement (diadakan penilaian Administrasi Awal) kemudian diadakan Visitasi kelembaga kemudian Rapat Pleno Penetapan Seperti Dalam Gambar Berikut ini :

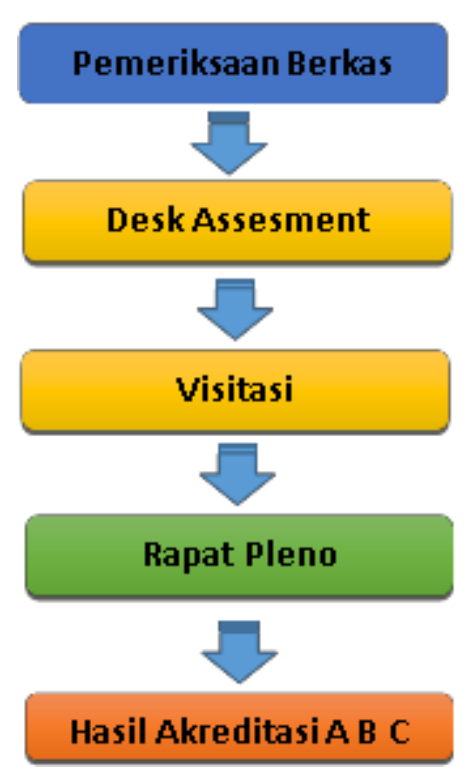

Tata Cara akreditasi
Dalam rangka peningkatan mutu, relevansi dan daya saing lembaga kursus dan pelatihan serta sebagai upaya memotivasi para penyelenggara kursus dan pelatihan, perlu dilakukan kegiatan penilaian kinerja lembaga kursus dan pelatihan secara bertahap, sistematis dan terencana. Dan berdasarkan hasil penilaian kinerja yang dilakukan terhadap lembaga kursus dan pelatihan dengan aspek-aspek penilaian yang ditetapkan, perlu ditetapkan kategori capaian kinerja Lembaga Kursus dan Pelatihan (LKP). Untuk mencapai katagori penilaian yang akurat maka diperlukan penelitian agar mengetahui hasil penilaian akreditasi LKP dengan mengunakan metode KNN adalah algoritma yang menentukan nilai jarak pada pengujian data testing dengan data training berdasarkan nilai terkecil Euclidean distance dan dioptimasi dengan Particle Swarm Optimization untuk mningkatkan akurasi .

\section{METODE PENELITIAN}

\section{Metode Pengumpulan Data}

Data sekunder adalah data yang diperoleh secara tidak langsung bersumber dari dokumentasi, literatur, buku, jurnal dan informasi lainnya yang ada hubungannya dengan masalah yang diteliti. Data sekunder pada penelitian ini adalah : buku-buku, jurnal tentang algoritma K-NN, Particle Swarm Optimization dan data mining serta data Data lembaga kursus sekalimantan selatan 2015 dan instrumen dari Badan Akreditasi Non Formal . Data primer adalah data yang diperoleh dari hasil penelitian. Data primer dalam penelitian ini adalah data hasil uji dengan menggunakan algoritma Knn Euclidean distance dan K-nn Euclidean distance optimasi Particle Swarm Optimization. 


\section{Rumusan Masalah}

Berdasarkan masalah diatas maka dapat disimpulkan algoritma Klasifikasi Particle Swarm Optimization

Pada Metode KNN dapat digunakan untuk membantu mengelompokkan data. Sedangkan pertanyaan penelitian (research questions) pada penelitian ini adalah: "Bagaimanakah Particle Swarm Optimization biasa memperoleh hasil yang optimal pada Metode KNN Euclidean distance, dengan menguji rumus variasi jarak untuk akreditasi lembaga kursus.

\section{Tujuan Penelitian}

Untuk memperoleh hasil yang optimal pada penilaian Akreditasi dengan rumus variasi jarak menggunakan algoritma $K-N N$ Euclidean distance dan optimasi Particle Swarm Optimization sehingga didapatkan tingkat akurasi terbaik pada hasil pengolahan data pada akreditasi Lembaga Kursus.

\section{Manfaat penelitian}

Penelitian ini dilakukan dengan harapan agar bisa memberikan manfaat tertentu baik bagi penulis, serta bagi pihak lain yang membutuhkan. Adapun manfaat dari penelitian ini adalah sebagai berikut:

\section{Manfaat Praktis}

Manfaat hasil penelitian ini adalah agar dapat menghasilkan dengan menggunakan algoritma K-NN Euclidean distance dan Particle Swarm Optimization menghasilkan nilai $\mathrm{A}, \mathrm{B}$, dan $\mathrm{C}$.

\section{Manfaat Akedemis}

Hasil penelitian ini diharapkan dapat memberikan gambaran dan pemahaman penerapan Klasifikasi algoritma k-NN Euclidean distance dan Particle Swarm Optimization untuk penilaian Akreditasi.

\section{Manfaat bagi Kebijakan Institusi}

Hasil penelitian ini diharapkan dapat membantu pihak terkait, yang dalam hal ini adalah pihak Dest Assement yang dilakukan Asseor dengan hasil data yang akurat dan akuntabel.

\section{Metode Pengolahan Data Awal}

Data yang didapatkan dari infokursus dan diambil data hanya untuk data lembaga kursus kalimantan selatan tahun 2015.

\section{Tabel Variabel Dan Katagori Penilaian}

\begin{tabular}{|c|c|c|c|c|}
\hline Variabel & Keterangan & Tipe & Nilai & Kategori \\
\hline \multirow{3}{*}{ Y } & \multirow{3}{*}{ Akreditasi } & \multirow{3}{*}{ Polynomial } & A & $\begin{array}{c}\text { Sangat } \\
\text { Baik }\end{array}$ \\
\hline & & & $\mathrm{B}$ & Baik \\
\hline & & & $\mathrm{C}$ & Cukup \\
\hline \multirow{5}{*}{$\mathrm{X}$} & \multirow{5}{*}{ Atribut } & \multirow{5}{*}{ Numeric } & 0 & $\begin{array}{c}\text { Sangat } \\
\text { Kurang }\end{array}$ \\
\hline & & & 1 & Kurang \\
\hline & & & 2 & Cukup \\
\hline & & & 3 & Baik \\
\hline & & & 4 & $\begin{array}{c}\text { Sangat } \\
\text { Baik }\end{array}$ \\
\hline
\end{tabular}

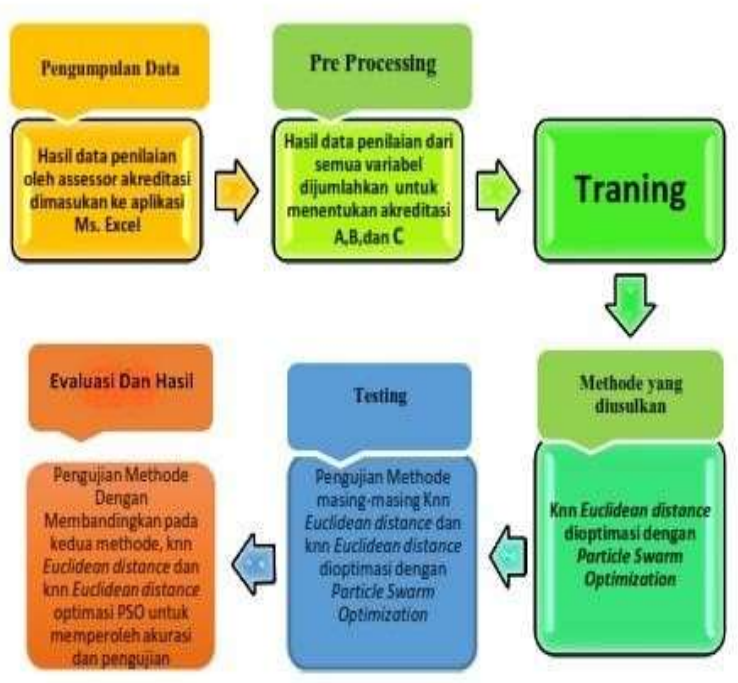

Metode Yang Diusulkan 


\section{HASIL DAN PEMBAHASAN}

HASIL Hasil Eksperimen dan Pengujian

Pengujian dengan menggunakan tehnik tehnik K-Nearest Neighbor Euclidean distance optimasi Particle Swarm Optimization. dengan tahapan pertama melakukan pengujian akurasi menggunakan K- Nearest Neighbor (KNN) Euclidean distance, sedang data yang diuji adapun data yang diuji adalah dataset data akreditasi Lembaga Kursus 2015. Pengujian dimulai dari 1,2,3,4,5,6,7,8,9, dan 10, mendapatkan hasil akurasi $96,60 \%$, tahap kedua pengujian meningkatdengan menggunakan dengan data yang di uji masih menggunakan data yang sama, Pengujian dimulai dari

1,2,3,4,5,6,7,8,9, dan 10. optimasi dilakukan dengan metode K-Nearest Neighbor Euclidean distance optimasi Particle Swarm Optimization Mendapatkan hasil tertingi $99,69 \%$.

\section{Algoritma $K-N N$}

Algoritma $K-N N$ adalah sebagai berikut: Algoritma k-NN menggunakan klasifikasi ketetanggaan sebagai nilai prediksi dari sampel uji yang baru Jarak yang digunakan adalah jarak Euclidean Distance. Jarak Euclidean adalah jarak yang paling umum digunakan pada data numerik Euclidean distance didefinisikan sebagai berikut :

\section{Euclidean distance}

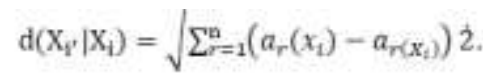

$$
\begin{aligned}
& \text { 1. Tentukan:| } \\
& \text { - Jarak Eucliedean }=d\left(x_{i}, x_{j}\right) \text {; } \\
& \text { - Record ke } \mathrm{i}=\left(x_{i}\right) \\
& \text { - Record ke } \mathrm{j}=\left(x_{j}\right) \\
& \text { - Dataker }=\left(a_{r}\right) \\
& \text { - } \mathrm{i}_{\mathrm{j}} \mathrm{j}=1,2,3, \ldots \ldots \mathrm{n} \text {; }
\end{aligned}
$$

\section{Rumus menentukan jarak Eucliedean Distance}

2 Algoritma k-NN adalah algoritma yang menentukan nilai jarak pada pengujian data testing dengan data training berdasarkan nilai terkecil dari nilai ketetanggaan terdekat didefinisikan sebagi berikut [6]: .

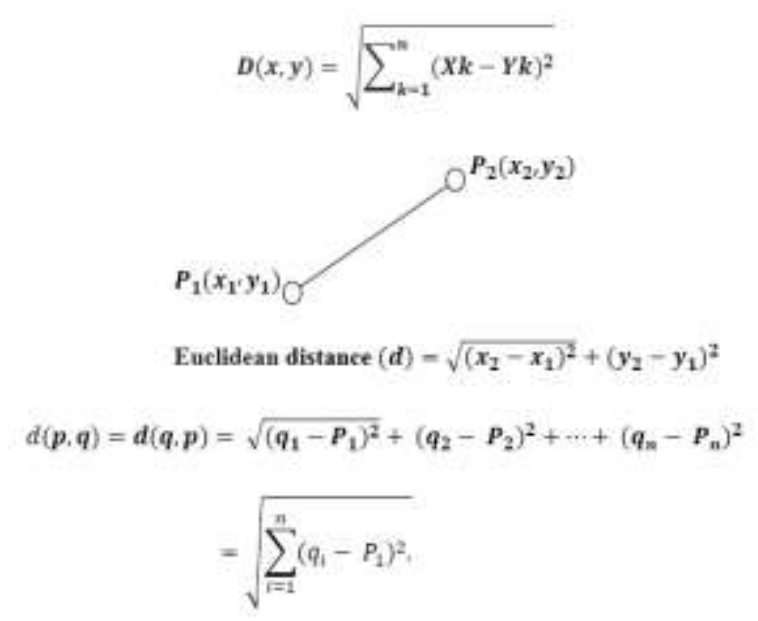

\section{Rumus variasi jarak pengujian} Eucliedean Distance

Jarak Euclidean atau metrik Euclidean adalah "biasa" (yaitu garis lurus) jarak antara dua titik dalam ruang Euclidean. Jarak Euclidean adalah jarak antara titik p dan $\mathrm{q}$ adalah panjang segmen garis yang menghubungkan mereka [6].

\section{Particle Swarm Optimization}

Optimasi adalah proses menyesuaikan kepada masukan atau karakteristik perangkat, proses matematis, atau percobaan untuk menemukan output minimum atau maksimum atau hasil. Input terdiri dari variabel, proses atau fungsi dikenal sebagai fungsi biaya, fungsi tujuan, atau kemampuan fungsi, dan output adalah biaya atau tujuan, jika proses adalah sebuah percobaan, kemudian variabel adalah masukan fisik untuk percobaan . 
Particle Swarm Optimization (PSO) adalah metode pencarian penduduk, yang berasal dari penelitian untuk pergerakan organisme dari kelompok burung atau ikan, seperti algoritma genetika, Particle Swarm Optimization (PSO) melakukan pencarian menggunakan populasi (swarm) dari individu (partikel) yang diperbaharui dari iterasi untuk literasi [11].Pengujian menggunakan K- Nearest Neighbor (KNN)

\section{Euclidean Distance}

Hasil validasi percobaan menggunakan KNearest Neighbor (KNN) Iecludian Distance terhadap data data akreditasi Lembaga Kursus 2015 dengan pengujian data yang niali $\mathrm{k}$ dimulai $1,2,3,4,5,6,7,8,9$ dan 10 kemudian dievaluasi dan dibandingkan dengan beberapa algoritma lain dengan hasil gambar diagram sebagai berikut :

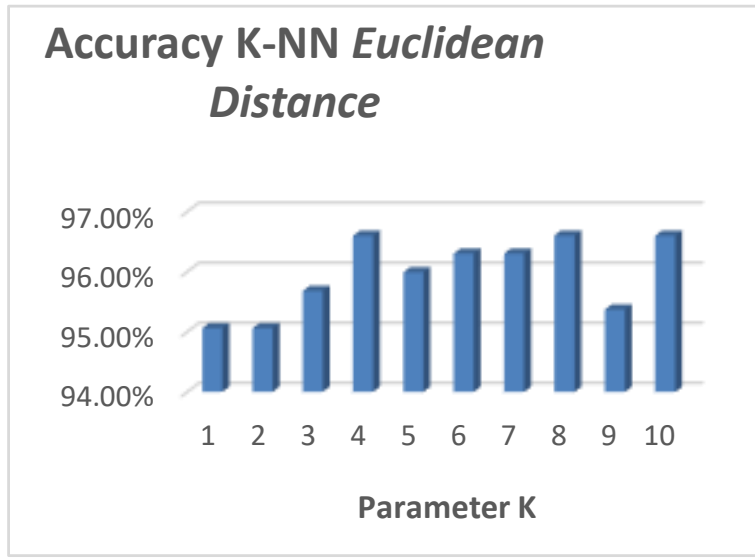

\section{Hasil Grafik Persentase K-NN Euclidean Distance}

Tabel Hasil Pengujian metode K- Nearest Neighbor Euclidean Distance

\begin{tabular}{|c|c|}
\hline $\mathrm{K}$ & Accuracy \\
\hline 1 & $95.06 \%$ \\
\cline { 2 - 2 } 2 & $95.06 \%$ \\
\hline 3 & $95.68 \%$ \\
\hline 4 & $96.60 \%$ \\
\hline 5 & $95.99 \%$ \\
\hline 6 & $96.30 \%$ \\
\hline 7 & $96.30 \%$ \\
\hline 8 & $96.60 \%$ \\
\hline 9 & $95.37 \%$ \\
\hline 10 & $96.60 \%$ \\
\hline
\end{tabular}

Hasil akurasi tertinggi yang didapat dari proses pengujian $\mathrm{K}$ - Nearest neighbor (KNN) Euclidean Distance sebesar 96,60 \% dengan nilai $K=4,8$, dan 10 , dari pengujian K - Nearest neighbor Euclidean Distance di atas dari percobaan itu maka peneliti mencoba melakukan pengujian lagi dengan K- Nearest optimasi Particle Swarm Optimization.

\section{Accuracy K-NN Euclidean Distance optimasi Particle Swarm Optimization}

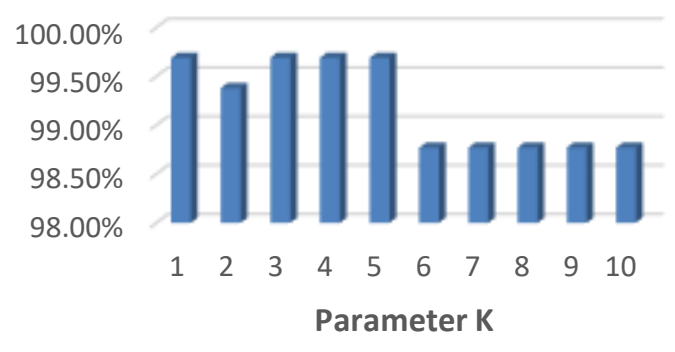

Hasil Grafik Persentase K-NN Euclidean Distance optimasi Particle Swarm Optimization.

Tabel Hasil Pengujian metode K- Nearest Neighbor Euclidean Distance optimasi Particle swarm Optimization

\begin{tabular}{|c|c|}
\hline $\mathrm{K}$ & Accuracy \\
\hline 1 & $95.06 \%$ \\
\hline 2 & $95.06 \%$ \\
\hline 3 & $95.68 \%$ \\
\hline 4 & $96.60 \%$ \\
\hline 5 & $95.99 \%$ \\
\hline 6 & $96.30 \%$ \\
\hline 7 & $96.30 \%$ \\
\hline 8 & $96.60 \%$ \\
\hline 9 & $95.37 \%$ \\
\hline 10 & $96.60 \%$ \\
\hline
\end{tabular}




\section{Evaluasi Dan Validasi Hasil}

Melakukan validasi dari hasil pengujian diatas dengan tehnik $(\mathrm{KNN})$ yaitu K-Nearest Neighbor (K-NN) Euclidean distance dan distance (KNN) K-Nearest Neighbor Berbasis Particle Swarm Optimization yaitu K-Nearest Neighbor Euclidean distance optimasi Particle Swarm Optimization, Tahap pertama didapatkan hasil akurasi dan dapat memastikan kategori nilai A, B, dan C, sedang data yang diuji seperti. Pengujian dimulai dari 1,2,3,4,5,6,7,8,9, dan 10, mendapatkan hasil akurasi tidak terlalu tinggi, dengan menggunakan data yang sama pengujian kedua, Pengujian dimulai dari 1,2,3,4,5,6,7,8,9, dan 10. optimasi dilakukan dengan metode K-Nearest Neighbor Euclidean distance optimasi Particle Swarm Optimization, perbandingan akurasi tertinggi $K$ - Nearest Neighbor (KNN) Euclidean distance dan $k$ - Nearest Neighbor (KNN) Euclidean distance, optimasi Particle Swarm Optimization mendapatkan hasil akurasi tertinggi.

Tabel Hasil Perbandingan Akurasi
\begin{tabular}{|c|c|l|}
\hline METODE & $\mathrm{K}$ & Accuracy \\
\hline $\begin{array}{c}\text { K-NN Validasi } \\
\text { Euclidean Distance }\end{array}$ & $\begin{array}{c}4,8, \text { dan } \\
10\end{array}$ & $96,60 \%$ \\
\hline $\begin{array}{c}\text { Optimasi PSO } \\
\text { Validasi } \text { K-NN } \\
\text { Euclidean Distance }\end{array}$ & $\begin{array}{c}1,3,4, \\
\text { dan } 5\end{array}$ & $99.69 \%$ \\
\hline
\end{tabular}

Dari tabel diatas dapat terlihat bahwa dengan menggunakan optimasi dapat meningkatkan hasil akurasi K- Nearest neighbor Euclidean distance dari 96,60\%, sampai 99,69\%. Dapat dilihat jelas adanya kenaikan yang dihasilkan yaitu sebesar 3,09 \%, namun dapat dilihat secara umum menggunakan KNearest neighbor Euclidean distance optimasi Particle Swarm Optimization lebih baik dari pada $K$ - Nearest neighbor Euclidean distance yang belum dioptimasi.

\section{Kesimpulan}

Berdasarkan hasil pengujian klasifikasi dan pembahasan, maka diperoleh kesimpulan :

Metode $K$ - Nearest Naighbor Euclidean distance menjadi lebih optimal dalam meningkatkan hasil akurasi apabila di dalam mengidentifikasi nilai akreditasi A, B dan C. optimasi dengan Particle Swarm Optimization, yang mampu memperoleh niali akurasi yaitu 99,69\% .

\section{Saran}

Penelitian ini mungkin akan dapat memberikan kontribusi lebih banyak, apabila metode perlu untuk pengembangan dengan

cara menerapkan K-nearest neighbor optimasi dengan Particle Swarm Optimization dalam suatu alat bantu berupa software android, sehingga dapat langsung diterapkan untuk meyelesaikan masalah

\section{DAFTAR PUSTAKA}

[1] Badan Akreditasi Nasional Pendidikan Non Formal "Instrumen Akreditasi Kursus dan Pelatihan “ Jakarta 2015

[2] Eugene Essa, Andrew Dittrich, Sergiu Dascalu, Frederick C. Harris, Jr. , ACAT: A Web-based Software Tool to Facilitate Course Assessment for ABET Accreditation. University of Nevada Reno Reno, NV USA, 2010.

[3] Hamid E. Najafabadi Student Member, IEEE Mohammad Ataei, and Mohamad F. Sabahi Member, IEEE, 2016

[4] Henny Leidiyana, 2013. Penerapan algoritma $\mathrm{k}$ nearest neighbor untuk penentuan resiko kredit kepemilikan kendaraan bemotor, 1(1), 65-76.

[5] Hidayah, N., 2013. Klasifikasi Penjurusan Program Studi Sekolah Menengah Atas dengan Algoritma 
[6] Ieee Uae Student Branch, Distances In Classification, 2016

[7] Indu Indah Purnomo, 2015, Klasifikasi Status Rumah Tangga Miskin dan Paling Miskin Mengunakan Algoritma K-Nearest Neighbor dan Seleksi Fituri Berbasis Chi Squared, UDINUS Semarang.

[8] Krisandi, N., Prihandono, B., \& Bayes, N. (2013). Algoritma k-nearest neighbor dalam klasifikasi data hasil produksi kelapa sawit pada pt . Minamas, 02(1), 33-38.

[9] Komang Sidhi Artha, Perbandingan Euclidean Distance, Dynamic Time Warping dan Eros dalam Klasifikasi Data Multivariate Time Series Menggunakan Knn, Ilmu Komputer Jurusan Ilmu Komputer Dan Instrumentasi Fakultas Matematika Dan Ilmu Pengetahuan Alam Universitas Gadjah Mada Yogyakarta, 2016

[10] Nazwar Fahmi, Analisis Dan Komparasi Algoritma Klasifikasi Data Mining Untuk Penentuan Resiko Kredit. Semarang, Indonesia, 2012.

[11] P. Y. D. Oskar Ika Adi Nugroho, "Segmentasi Citra Aksara Jawa Menggunakan Algoritma Particle Swarm Optimization," Seminar Nasional Teknologi Informasi dan Komunikasi 2014 (SENTIKA 2014), Vols. ISSN: 2089-9813, pp. 1-5, 2014

[12] Ratih Suminar, Bambang Hidayat, Ratri Dwi Atmaja, Klasifikasi Kualitas Beras Berdasarkan Ciri Fisik Berbasis Pengolahan Citra Digital.Teknik Elektro, 2012.

[13] Sugianti D., 2012. Algoritma Bayesian Classification Untuk Memprediksi Heregristrasi Mahasiswa Baru Di
[14] Syamsul Bahri, Klasifikasi Kendaraan Roda Empat Berbasis Knn, Amik Bsi Yogyakarta, 2016.

[15] Tongliang Liu and Dacheng Tao, Fellow, IEEE, 2016 